\title{
Vaginal Dermoid Cyst
}

National Cancer Institute

\section{Source}

National Cancer Institute. Vaginal Dermoid Cyst. NCI Thesaurus. Code C128113.

A rare benign cystic teratoma that arises from the vagina. It presents with a slow growing cyst in the vaginal wall that contains sebaceous material and hair. The cyst is lined by squamous epithelium. Skin adnexal structures and sometimes smooth and skeletal muscle are present. 